\title{
Saussure: leitor de Platão
}

\section{Saussure: Plato's reader}

Thomas Rocha ${ }^{1}$ 1 Mestre em Linguística pela Pontifícia
Universidade Católica do Rio Grande do Sul.

E-mail: thomas.rocha@acad.pucrs.br
RESUMO: Neste trabalho, propomo-nos a fazer um estudo que coloca em relação a teoria da alteridade, elaborada por Platão no diálogo Sofista, e a teoria do valor linguístico apresentada no Curso de linguística geral (CLG) de Ferdinand de Saussure. Partimos da hipótese levantada por Oswald Ducrot de que, ao desenvolver a noção de valor linguístico, Saussure aplica ao estudo da linguagem o que Platão disse sobre as Ideias. Profundo conhecedor da filosofia clássica, Ducrot encontrou, na teoria do valor linguístico, a fundamentação que o lançou na pesquisa linguística e que hoje conhecemos pelo nome de Semântica Argumentativa. Segundo Ducrot, na teoria da alteridade concebida por Platão encontramos a origem filosófica da teoria saussuriana do valor. Nossa intenção é, partindo de um estudo minucioso do diálogo Sofista e do CLG, circunscrever a concepção de diferentes conceitos que, por sua vez, pertencem a diferentes campos do conhecimento: a filosofia e a linguística. Dessa forma, é de uma perspectiva epistemológica que nos colocamos. Foi através desses textos que Ducrot pode relacionar a ideia de alteridade com a noção de valor, ao encontrar em ambas, a ideia de "oposição" como constitutiva das entidades a serem analisadas. De modo que, ao investigar e aprofundar a noção de valor tentamos explicitar as influências filosóficas que fundamentaram o conceito desenvolvido pelo linguista genebrino.

Palavras-chave: Alteridade; Valor linguístico; Platão; Saussure; Ducrot.

ABSTRACT: This article aims to address the nexus between the theory of alterity developed by Plato in his Sophist dialogue and the theory of linguistic value introduced by Ferdinand de Saussure in his Course in General Linguistics (CGL). It departs from the hypothesis raised by Oswald Ducrot that Saussure, by developing the notion of linguistic value, applies in the study of language what Plato stated about ideas. Ducrot-an expert in classical philosophy-draws in the linguistic value theory to develop the branch in linguistic studies known as argumentative semantics. According to Ducrot, it is possible to find the philosophical origin of Saussure's theory of value in Plato's theory of alterity. The article intends to draw on a detailed study on the dialogue between Sophist and CGL to circumscribe concepts belonging to different fields of study: philosophy and linguistics. Thus, it aims an epistemological perspective. By the means of the aforementioned works, Ducrot set a nexus between the idea of alterity and the notion of value by finding in both the idea of "opposition" as constitutive of the issues under analysis. Through the investigation and the deepening of the understanding on the notion of value, it tries to reveal the philosophical influences under the concept developed by the Genebrian linguist.

KEYwoRDS: Alterity; linguistic value; Plato; Saussure; Ducrot. 


\section{Introdução}

$\mathrm{N}$

o tortuoso caminho em busca das relações entre linguagem e nconsciente e, por conseguinte, entre linguística e psicanálise, Arrivé (1999) reconhece que sonhou em reconstituir a leitura que Lacan teria feito do Curso de Linguística Geral (doravante CLG) quando, no início dos anos 50, ele inicia a "tardia" junção entre alguns dos conceitos fundamentais do aparato teórico de dois gênios contemporâneos, estranhamente desconhecidos um do outro: Saussure e Freud.

Contudo, Arrivé logo se deu conta da impossibilidade de tal reconstituição, renunciando à sua execução e propondo, "mais modestamente", uma releitura de Saussure que, talvez, esclarecesse "certos aspectos da leitura que dele faz Lacan" (1999, p. 33). Embora, de nossa parte, reconheçamos que nos seria extremamente gratificante e proveitoso reconstituir a leitura que Oswald Ducrot fez do $C L G$, nos anos 60, quando, diante da necessidade de ministrar aulas sobre "O Estruturalismo", ele encontrou algo que o lançaria na pesquisa linguística e nortearia todo o seu trabalho em semântica: a noção de valor linguístico ${ }^{1}$.

No "Prefácio" ao livro de Carlos Vogt, intitulado O intervalo semântico (2009), Ducrot afirma que, no capítulo sobre o valor, Saussure aplica às palavras da língua o que Platão disse sobre as Ideias. Profundo conhecedor da filosofia clássica, Ducrot reconhece que a teoria saussuriana do valor está fundamentada filosoficamente na teoria da alteridade concebida por Platão e apresentada no diálogo Sofista: "a oposição, para Saussure, é constitutiva do signo da mesma forma que a alteridade é, para Platão, constitutiva das ideias" (DUCROT, 2009, p. 10-11).

Ver DUCROT, Oswald. La Sémantique Argumentative peut-elle se réclamer de Saussure? In SAUSSURE, Louis de (org.). Nouveaux regards sur Saussure. Genebra: Librairie Droz S. A., 2006.
Em vista disso, nos perguntamos: será possível identificar em Saussure elementos que remetam à teoria da alteridade de Platão? Não temos aqui a pretensão de pôr à prova a hipótese de Ducrot, pelo contrário, tentaremos apenas explicitá-la. Neste texto, nos propomos a fazer um estudo que coloque em relação a teoria da alteridade, elaborada por Platão no Sofista, e a teoria do valor apresentada no CLG de Ferdinand de Saussure. Objetivamos demonstrar em que medida a noção de valor foi constituída a partir do princípio consagrado na referida obra de Platão.

Fundamental para a descrição e explicação do sentido na linguagem, a noção de valor ressalta a natureza opositiva do signo. Ao falar em valor linguístico, Saussure destaca o fato de que a relação significante/significado deve ser sempre considerada à luz do sistema linguístico em que o signo se insere. Dessa forma, a noção de valor permite que se analise a língua a partir das suas relações, descobrindo em si o fundamento da sua significação, sem recorrer a elementos de ordem extralinguística. 0 sentido dos termos da língua se fundamenta nas suas relações.

Para atingir nosso objetivo, focaremos o trabalho na análise e comparação dos textos Sofista, de Platão e Curso de linguística Geral (CLG) de Saussure. Foram justamente esses textos que possibilitaram a Ducrot relacionar a alteridade com a noção de valor, ao encontrar, em ambos, a ideia de "oposição" como constitutiva das entidades a serem analisadas. São, portanto, os materiais que trazem de modo mais explícito o pensamento dos autores a respeito das noções que pretendemos estudar.

Partindo de um estudo minucioso desses textos, nossa intenção é circunscrever a concepção de diferentes conceitos que, por sua vez, pertencem a diferentes campos do conhecimento: a filosofia e a linguística. Tanto Platão quanto Saussure são fundadores de discursos que ecoam na posteridade. São textos que dialogam com as teorias que ajudam a constituir, de modo que tentaremos colocar em contraponto toda essa interdiscursividade. 
É importante destacar que estamos relacionando a produção de autores separados por mais de vinte séculos de história. Separados pelo tempo e por línguas muito distintas, não podemos falar de termos ou definições comuns a ambos. Contudo, podemos falar de princípios ou ideias que permeiam a construção teórica desses autores e que nos permitem elucidar aspectos comuns, relativos às condições de emergência de cada uma das obras.

Na primeira parte, dedicamos algumas palavras ao contexto no qual o diálogo Sofista foi escrito, compreendendo seu lugar na obra platônica e, ao mesmo tempo, dando um destaque especial à construção do que chamamos hoje de teoria da alteridade. Na segunda e última parte, adentramos na obra do linguista genebrino, focalizando nossa atenção na teoria do valor linguístico, na tentativa de encontrar elementos que remetam a uma possível influência do pensamento de Platão na linguística desenvolvida por Saussure.

\section{Ser o que os outros não são: a alteridade de Platão}

Nas palavras de Rogue, a "filosofia platônica nasce de um escândalo" (2011, p. 7), o da morte de Sócrates em 399 a.C. Toda a obra de Platão (427? a.C.-347? a.C.) é posterior a essa data. Em seguimento ao seu mestre, Platão retoma uma investigação cujo objetivo final é encontrar a combinação entre o $\log _{0}{ }^{2}$ e as coisas. Segundo a mitologia grega, a linguagem é um dom divino que foi concedido aos homens para dizer o ser e as coisas essencialmente como elas são:

Falar é dizer o ser, é refletir o kósmos, tal como ele é, por meio do instrumento que os deuses nos deram para este fim. Como a linguagem reflete as coisas tais como elas são, uma ação injusta nunca seria louvada, o verdadeiro nunca seria confundido com o falso, a aparência nunca levaria vantagem sobre o ser. (...) 0 lógos dizia as coisas assim como eram, e os homens tinham apenas de confiar nele (ROGUE, 2011, p. 9).

${ }^{2}$ Embora o termo grego lógos possa abranger uma série de noções (definição, proposição, palavra, etc.), os autores aqui citados adotam a acepção que o relaciona à ideia de linguagem e/ou discurso.
No entanto, a Atenas dos séculos V-IV a.C. está no seu apogeu e o lógos ocupa um lugar central: para existir como cidadão é preciso saber falar. $O$ que se evidencia com o privilégio concedido aos sofistas, sábios que ensinam a arte de bem falar aos aprendizes ricos da cidade. Para os sofistas, "o valor do discurso é absoluto, a "verdade" é o que ele diz e, portanto, é relativa. Discurso e verdade se identificam, subordinando-se esta àquele, e, desse modo, está garantida a verdade de tudo o que é dito" (NEVES, 1987, p. 38-39).

Nesse sentido, o discurso sofístico não é um discurso do ser, não é um discurso filosófico. Ao contrário, a atividade sofística por excelência é a retórica, de modo que ao discurso cabe somente a função de persuadir, de produzir a aparência de grandeza, de verdade, de justiça e de força de uma causa. "Não importa ter razão e defender uma causa justa, mas importa saber fazer ver como justa a causa que o discurso defende" (idem, p. 39).

Ainda de acordo com Neves, em decorrência da natureza de sua atividade, os sofistas criam a ideia da superioridade, da autonomia do lógos: "o que é dito é o que é pensado, e o pensamento se reduz à linguagem” (1987, p. 42). Em outras palavras, como não há distância entre a linguagem e seu objeto, não se vislumbra a necessidade de se investigar uma verdade para além da palavra, sendo, portanto, impossível enunciar o falso. Nesse contexto, "não é apenas a linguagem que se encontra desviada; é o próprio ser, do qual não se sabe mais o que dizer, se ele é um ou múltiplo, até mesmo se existe" (ROGUE, 2011, p. 10).

É justamente esse desvio do discurso, do lógos, que Sócrates não aceita. 0 fundamento da filosofia socrática é recusar o aviltamento do discurso, numa busca incessante pelo lógos justo, íntegro, que seja a expressão do próprio ser das coisas. Pois quem puder definir apropriadamente a justiça, por exemplo, será necessariamente justo, porque ao compreender a definição, ninguém poderia cometer uma injustiça. Exatamente por recusar os belos discursos, que não dizem nada sobre o ser, mas que tanto encantavam os atenienses, Sócrates foi condenado à morte. 
Conforme Rogue, esse "esforço de definição, de reaplicação da linguagem ao ser, que Platão empreende seguindo a Sócrates, vai levá-lo a esse momento fundamental que é a constituição do dualismo ontológico" (2011, p. 12-13), isto é, a ideia de que há dois níveis distintos de realidade, o sensível e o inteligível.

De um lado, o mundo sensível, aquele que podemos apreender pelos sentidos, o mundo material. De outro lado, o mundo inteligível, aquele que só podemos apreender pelo raciocínio, pela inteligência, trata-se do mundo mental, metafísico. As formas inteligíveis, as Ideias, "são realidades imutáveis e universais, independentes dos intelectos que as percebem" (BRISSON; PRADEAU, 2010, p. 59). As formas inteligíveis (eîdos ou idéa) são a causa, a origem, o modelo das coisas sensíveis, que, por sua vez, não passam de imagens. Imagens que ganham uma existência própria: dizer uma coisa não é mais necessariamente dizer o que é. Consequentemente, o lógos é "separado" da realidade. A dissociação entre a linguagem e as coisas é o que permitirá a Platão eleger a linguagem como objeto de investigação.

Contrapondo-se à concepção sofística que apregoa que a linguagem só conduz a si mesma e, assim, basta falar para dizer verdade, "Platão apresenta uma concepção filosófica segundo a qual a linguagem conduz a alguma coisa que não ela mesma e, portanto, o discurso pode dizer ou não dizer verdade" (NEVES, 1987, p. 45). Os diálogos platônicos que colocam em questão o problema da linguagem são especialmente o Crátilo e o Sofista.

Em geral, os comentaristas das obras de Platão elegem o Crátilo como o texto básico do pensamento grego sobre a linguagem. Nesse diálogo, encontramos a discussão em torno de duas teses opostas: os "naturalistas" versus os "convencionalistas". Segundo Camara Jr. (2011, p. 24), os naturalistas, representados por Crátilo, defendem a ideia de que a linguagem se impõe aos homens por uma necessidade da natureza, enquanto que os convencionalistas, representados por Hermógenes, creem que a linguagem tem origem no poder de julgamento dos homens.

Na verdade, conforme Neves nos explica, o problema central do diálogo assenta-se em um terreno mais amplo que o da linguagem. "No fundo, é o problema da essência do homem, sua relação com a natureza. A natureza (phýsis) e o que o homem faz (nómos) não são entidades absolutas, configurações fixas e estanques" (1987, p. 46). Em oposição à tese de Protágoras, que afirma que o homem é a medida de todas as coisas, Platão sustenta que as coisas existem por si mesmas, de acordo com sua essência natural, ou seja, "há nas coisas em si mesmas uma certa firmeza, uma essência permanente, que não depende de nós e de nosso modo de vê-las. Há, pois, um eîdos, uma "ideia" das coisas" (idem, p. 46). As palavras de Paviani são esclarecedoras quanto a isso:

Platão definitivamente é um essencialista. As coisas e as ações possuem uma essência. 0 nome é uma mimesis fonética do objeto, mas deficiente. No entanto, a solução do problema da verdade sobre a justeza dos nomes não é explicitada por Platão. Sua posição está presente na teoria do eîdos implícita do início ao fim do diálogo. Por isso, o verdadeiro tratado sobre a linguagem não é o Crátilo, mas o Sofista e passagens do Parmênides e outros diálogos da maturidade (1993, p. 43).

Significa que o exame que Platão faz da linguagem não se restringe à investigação da relação entre o nome e a coisa, mas passa à verificação da relação entre o lógos e a ousía. E é justamente no Sofista que a investigação deixa de centralizar-se na nominação, e a função de mimese se atribui ao lógos. Estamos, portanto, diante de dois modos diferentes de interpretar a relação que se estabelece entre discurso e ser: "(i) o que é é independente do que se diz dele ou (ii) o que é é apenas aquilo que se diz que ele é" (SOUZA, 2009, p. 15).

De um lado, defendendo a interpretação (i) estão Parmênides e Antístenes; de outro, defendendo (ii) estão os sofistas, representados por Górgias e Protágoras. Para os sofistas é impossível transmitir o conhecimento 
por meio do discurso, enquanto que para Platão o ser é anterior ao discurso que, como vimos, diz o ser das coisas, pois as coisas são como são, independentemente da opinião ou de elementos circunstanciais. Estas duas interpretações delimitam o cenário em que o Sofista foi escrito.

Segundo Cordero (1993, p. 19), o título do diálogo é mais ambíguo do que parece. Isso porque conhecendo a rivalidade existente entre os filósofos e os sofistas, não se pode esperar de um diálogo platônico intitulado Sofista nada mais nada menos do que uma severa crítica à sofística. De fato, encontramos uma série de definições (seis ou sete) que contestam, denunciam e até ridicularizam a postura e conduta dos sofistas. Todavia, mais importante do que isso, encontramos, no Sofista, uma sistematização das questões ontológicas tradicionais na busca de uma síntese que ultrapasse as aporias e revele uma nova concepção do ser. Compreende-se, desse modo, a razão do subtítulo do diálogo: "Sobre o Ser".

Assim, a busca pela definição do sofista, proposta por Sócrates ${ }^{3}$ no início do diálogo, levará o Estrangeiro de Eleia a uma profunda investigação da noção de ser com o intuito de desmascarar a sofística. Na opinião de Cordero (1993, p. 17), trata-se de um verdadeiro manifesto em defesa da filosofia. A filosofia está doente. Um fosso intransponível separa o sensível do inteligível. "A identidade pura dos inteligíveis" está isolada, separada do todo, "lá no alto do céu" (ROGUE, 2011, p. 93); é preciso, portanto, superar essa ruptura. "A tentativa de separar tudo de tudo o mais não só é sinal de mau gosto, como também indica que uma pessoa é completamente inculta e não filosófica" (Sofista, 259e) $)^{4}$.

\footnotetext{
3 As personagens do diálogo são Teodoro, Sócrates, um estrangeiro de Eleia e Teeteto.

${ }^{4}$ Com relação às citações do diálogo Sofista de Platão: os números indicam a página da edição referencial de Henri Estienne (Stephanus), as letras ( $a, b, c, d$ e) remetem ao parágrafo a que se faz men

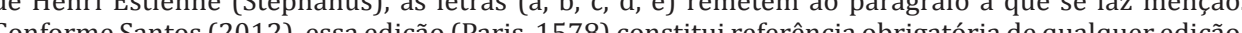
Con facilita e agiliza a consulta a outras traduções.
}

De acordo com Paviani (1997), o tema geral do Sofista "consiste na tentativa de dizer, positivamente, quem é o sofista para, negativamente, caracterizar o filósofo" (p. 941). Dessa forma, "um se mostra 'dialeticamente' no outro" (ibidem, p. 938) e o tema acaba por se transformar numa questão de investigação das relações entre o ser e o não-ser, entre as Formas inteligíveis e o mundo sensível.

Estrangeiro: Estamos, meu caro amigo, realmente empenhados numa investigação muito difícil, pois a matéria de aparecer e parecer, mas não ser, e de dizer coisas, mas não verdadeiras - tudo isso é agora, como o foi sempre motivo de muita perplexidade. Sabe, Teeteto, é sumamente difícil compreender que forma de discurso um indivíduo deveria usar para dizer que realmente há a falsidade e, ao dizê-lo, não se envolver em contradição (Sofista, 236e). ${ }^{5}$

Ao buscar uma definição que apreenda o verdadeiro núcleo da atividade sofística, o Estrangeiro e Teeteto (seu interlocutor direto) deparam-se com a imperiosa necessidade de "uma reflexão sobre as aparências, sobre o estatuto dos fenômenos, sobre a verdadeira realidade das coisas, isso é, sobre o ser" (CORDERO, 1993, p. 21). O objetivo de Platão é encontrar uma definição que revele que o sofista não passa de um falsário, um enganador. Entretanto, um obstáculo se apresenta: o axioma de Parmênides segundo o qual o não-ser não existe.

Estrangeiro: Porque essa afirmação ${ }^{6}$ implica a hipótese audaciosa de que $o$ não-ser existe, pois se assim não fosse a falsidade não poderia vir a ser. Mas o grande Parmênides, meu rapaz, do tempo em que éramos crianças até o fim de sua vida, nunca deixou de protestar contra isso e repetiu continuamente tanto em prosa quanto em verso: Nunca te submeta ao pensamento de quedisse ele - o não-ser é; Mas mantém tua inteligência afastada dessa senda de investigação (Sofista, 237a).

5 As citações do diálogo Sofista foram retiradas da seguinte edição: PLATÃO. Diálogos I: Teeteto (ou Do conhecimento), Sofista (ou Do ser), Protágoras (ou Sofistas). Tradução, textos complementares e notas: Edson Bini. Bauru, SP: Edipro, 2007.

6 Isto é, afirmar que se pode enunciar o falso. 
Assumindo o axioma eleático como verdadeiro, o sofista não pode ser considerado um falsário, visto que não se pode dizer o que não existe. "Platão põe à prova essa tese... e não encontra nada para criticar!" (CORDERO, 1993, p. 23), pois falar de alguma coisa que não é equivale a dizer nada. Esse raciocínio implica a ideia de que só seria possível dizer, de uma coisa, aquilo que ela é. Por outro lado, segundo Souza (2009), dizer o que uma coisa $e ́$ envolve um outro problema, que a autora chama de argumento contra a possibilidade da predicação:

Não se pode dizer que $\mathrm{A}$ é $\mathrm{B}$, porque $\mathrm{A}$ é diferente de $\mathrm{B}$ e, portanto, não é $\mathrm{B}$. Ao predicar B de A eu digo, desta coisa A, aquilo que ela não é, e dizer o que uma coisa não é é dizer o falso. Então, de uma coisa $\mathrm{A}$, eu só posso dizer que é A. Não há, pois, nenhuma afirmação verdadeira que não seja uma tautologia, mas tautologias não informam nada sobre o ser de uma coisa (SOUZA, 2009, p. 19).

Sendo assim, Platão se vê diante de um paradoxo: ao afirmar que o sofista "possui uma arte, por assim dizer, de produzir aparências, ele facilmente se aproveitará de nossa pobreza terminológica para executar um contraataque, distorcendo o sentido de nossas palavras, ou seja, atribuindo a elas o sentido contrário" (Sofista, 239d). Faz-se necessário, portanto, encontrar um lugar para os produtos da atividade sofística: as cópias, as imagens, as imitações, as ilusões.

A constatação a que chegam, o Estrangeiro e Teeteto, é a de que a imagem "é uma outra coisa confeccionada semelhante à coisa verdadeira" (Sofista, 240a). Mas, o que é semelhante, "ainda que não realmente seja, realmente é" (idem, 240b). "Parece realmente que o não-ser de algum modo enredou-se no ser, o que é muito estranho e absurdo" (id., 240c). "É claro que é absurdo", é preciso "reconhecer que, de um certo modo, o não-ser é (existe)" (id., 240c). Como o ser pode conviver com seu contrário? Um novo desafio se impõe ao Estrangeiro e seu interlocutor. Se a investigação sobre o não-ser não os impediu de chegar a uma contradição, será preciso rever o que se sabe sobre o ser:

Estrangeiro: Mas talvez nossas mentes estejam em idêntica condição no que toca também ao ser. É possível que pensemos que dispomos de clareza quanto a esse termo e que compreendemos quando é empregado, embora fiquemos confusos com a expressão não-ser. Mas talvez, na realidade, compreendamos igualmente pouco de ambas essas expressões (Sofista, 243c).

Na busca por uma compreensão mais adequada sobre o ser, Platão "examina rigorosamente as soluções propostas por todos os sistemas filosóficos” (CORDERO, 1993, p. 22), inclusive o dele até aquele momento. Conforme Souza (2009), uma mesma compreensão de ser e não-ser perpassa as teorias filosóficas que Platão analisa. Para Parmênides, representante da filosofia eleata, ser assume o significado de ser idêntico. "Os sofistas, por sua vez, quando argumentam que o lógos não diz o ser, o fazem considerando o ser do mesmo modo que ele é entendido por Parmênides, uno e separado" (p. 105). "Eles não viram que o que é isolado degenera e morre" (CORDERO, 1993, p. 25).

Até então, a filosofia encarava a realidade existente como "uma espécie de "coisa" (mesmo "ideal"), como um "objeto" que é preciso definir ou descrever, cujo número e qualidades são apreensíveis e exprimíveis" (ibid., p. 22). O ser era visto como "uma entidade absoluta (simples ou múltipla), total, cuja negação é inconcebível, já que o não-ser não pode existir" (ibid., p. 22). É preciso, portanto, "torná-los melhores do que são" (Sofista, 246d), levando-os a reconhecerem uma nova concepção de ser, um ser que leva as realidades (corpórea ou incorpórea, sensível ou inteligível) a se combinarem, a se mesclarem, um ser que se torna uma verdadeira potência: 
Estrangeiro: 0 que sugiro é que tudo aquilo que possui potência de qualquer espécie, quer para produzir uma mudança em algo de qualquer natureza, quer para sofrer o efeito da mais ligeira causa mesmo no mais ínfimo grau, ainda que o seja numa única oportunidade, é. Estabeleço como definição do ser que ele é nada mais nada menos que potência (Sofista, 247e).

É justamente a definição do ser como "potência de produzir ação ou sofrer ação" (Sofista, 248c) que permite que as realidades se misturem, e é devido a essa mistura que as coisas são. No entanto, a sequência da argumentação leva Platão a um novo impasse: não se pode admitir que todas as coisas sejam capazes de mútua combinação. Do contrário, deveria se admitir, por exemplo, que o movimento se combine com o repouso, mas isso é impossível. "Porque, nesse caso, o movimento estaria em repouso e o repouso estaria em movimento" (Sofista, 255a). Diante desse impasse, Platão empreende o inventário dos gêneros supremos:

Estrangeiro: Como, portanto, concordamos que alguns gêneros mesclar-seão entre si, enquanto outros não se mesclarão, e alguns se mesclarão com poucos e outros com muitos, e que nada há que impeça alguns de se mesclarem universalmente com todos, prossigamos com nossa discussão investigando não a totalidade das formas ou ideias, com o que ficaríamos confusos entre tantas, mas apenas algumas, fazendo uma seleção das consideradas as mais importantes (Sofista, 254c).

Platão inicia a análise a partir do Ser, do Movimento e do Repouso, examinando suas várias naturezas e detendo-se em sua capacidade de mútua combinação:

Estrangeiro: Com certeza, os mais importantes gêneros são precisamente os que mencionamos, a saber, o próprio ser, o repouso e o movimento. [...] E, ademais, dois deles - segundo dizemos - não podem mesclar-se. [...] Mas o ser pode mesclar-se com ambos, uma vez que ambos são. [...] Assim, cada um deles é diferente dos dois restantes, mas idêntico a si mesmo (Sofista, 254d).
Dois outros gêneros surgem, o Idêntico (o Mesmo) e o Diferente (o Outro). Após essa minuciosa análise, Platão descobre, em contraposição à tese de Parmênides, que "o não ser de cada ser é uma realidade que se lhe opõe, isto é, o não ser é o outro (a Diferença) fragmentado entre os seres segundo a reciprocidade da sua relação" (PAVIANI, 1993, p. 47). É essa potência de comunicação com outras Formas, outras realidades, que permite que alguma coisa constitua sua essência: "toda coisa é, de fato, o mesmo que ela própria, e diferente das outras; eis seus limites, isto é, sua essência” (CORDERO, 1993, p. 25).

Dentre os dois novos gêneros, o Diferente (Outro) se destaca, pois "possui uma natureza absolutamente singular, que o distingue radicalmente dos anteriores, e que faz dele, por assim dizer, o gênero dos gêneros e o fundamento de todos os outros (DUCROT, 2009, p. 10):

Estrangeiro: Portanto, é necessário que estabeleçamos a natureza do diferente como um quinto gênero entre aqueles nos quais selecionamos nossos exemplos. (...) E diremos que permeia a todos, uma vez que cada um deles é diferente dos demais, não por razão de sua própria natureza, mas porque partilha da forma ou ideia do diferente (Sofista, 255e).

Como veremos na próxima parte, esse papel constitutivo da alteridade subjaz de tal modo ao estruturalismo saussuriano" que "ser estruturalista, no estudo de um domínio qualquer, é definir os objetos desse domínio uns em relação aos outros (...). Admite-se, assim, que algumas de suas

7 A expressão "estruturalismo saussuriano" é aqui utilizada com base na caracterização dada por Ducrot às reformulações introduzidas no estudo da Linguística pelo linguista genebrino Ferdinand de Saussure. Referimo-nos, especialmente, à organização inerente a toda língua, a qual Saussure denomina sistem (seus sucessores falam de estrutura), cujos elementos não têm nenhuma realidade independentement (seus sucessores falam de estrutura), cujos elementos não têm nenhuma realidade independentemente de sua relação com o todo (ver o verbete "saussurianismo" no Dicionário Enciclopédico das Ciências da Linguagem (2010, p. 25-29), cf. referências bibliográficas). Para uma caracterização mais abrangente do "estruturalismo saussuriano" ver DUCROT, Oswald. Estruturalismo e linguistica. Trad. José Paulo Paes. 
mútuas relações não são uma consequência da sua natureza, mas que elas a constituem" (DUCROT, 1987, p. 67).

É importante registrar que, após investigar a natureza dos principais gêneros, Platão finda sua pesquisa com o inventário dos cinco gêneros (Ser, Movimento, Repouso, Mesmo e Outro) por considerá-los suficientemente representativos da relação existente entre as Formas. Além disso, eles se mostram úteis para explicar a existência do não-ser, visto que o nãoser é definido como o diferente, o outro, a alteridade: "Assim, no que toca ao movimento, o não-ser necessariamente é, estendendo-se isso a todos os gêneros, uma vez que em todos a natureza do diferente opera de tal maneira a tornar cada um diferente do ser e, portanto, não-ser" (Sofista, 256e).

Sendo assim, conforme Neves, "cada um dos gêneros pode corretamente ser chamado não-ser, e, ao mesmo tempo, pelo fato de participar do ser, cada um deles pode ser chamado ser" (1987, p. 56), de modo que se pode concluir que, "relativamente a cada um dos gêneros, o ser é multiplo e o nãoser é numericamente infinito" (Sofista, 256e). No entanto, "quando dizemos não-ser nos referimos, suponho, não a algo que seja o oposto do ser, mas somente a algo diferente" (ibidem, 257b), portanto, "quando nos disserem que o negativo significa o oposto, discordaremos. Somente admitiremos que a partícula não indica algo diferente das palavras às quais serve de prefixo, ou melhor, diferente das coisas às quais os nomes que se seguem à negação são aplicados" (ibid., 257c).

É precisamente no que diz respeito à negação que, segundo Cordero, Platão é revolucionário: "a negação não significa 'contradição' (ou oposição); ela significa 'diferença'. Uma coisa (um fato, um estado de coisas) negada é uma realidade diferente daquela que se negou. Ela é, no entanto, tão real quanto seu equivalente 'positivo'” (1993, p. 56). Relacionando o não-ser com a questão da negação, Platão institui o primado da alteridade: "em cada realidade, há uma mistura de ser e de não-ser, pois toda coisa é o que é, mas também é tudo o que ela não é" (CORDERO, 1993, p. 60). As palavras do Estrangeiro ressaltam essa realidade:

Estrangeiro: Não nos limitamos, contudo, a mostrar que as coisas que não são são. Indicamos, inclusive, o que é a classe do não-ser, uma vez que mostramos que a natureza do diferente é e está distribuída em pequenos fragmentos entre todas as coisas que são nas suas relações recíprocas. Ousamos dizer ademais, que cada parte do diferente, que é contrastada com o ser, é realmente exatamente não-ser. (Sofista, 258e)

A definição do não-ser como alteridade é o que permite a Platão contestar o axioma de Parmênides e estabelecer a relação entre discurso e não-ser: "consideramos que o não-ser era um dos gêneros do ser, permeando todas as coisas que são. [...] Portanto, o próximo passo é indagar se ele se mescla com a opinião e o discurso" (Sofista, 260b). Pois, "se não se mesclar com eles [a opinião e o discurso], resultará necessariamente que tudo é verdadeiro; mas se houver mescla, serão gerados a falsa opinião e o falso discurso" (idem, 260c). Logo, "se existe falsidade, existe engano. [...] E se existe engano, tudo necessariamente estará doravante repleto de cópias, semelhanças e aparições" (id., 260c). Assim, Platão encontra uma explicação para os enunciados falsos e, agora, o sofista pode ser acusado de enganador, falsário, ilusionista.

Analisar a natureza do discurso é, portanto, a última tarefa que se impõe, visto que é preciso "perceber com clareza sua participação com o não-ser. Munidos dessa percepção, poderemos demonstrar que a falsidade é (existe) e, uma vez conquistada essa demonstração, será aí que prenderemos o sofista" (Sofista, 261a).

Ao estabelecer o discurso como um dos gêneros do ser, "afinal, se dele fôssemos privados, seríamos privados da filosofia, o que constituiria o supremo desastre" (Sofista, 260a), Platão desenvolve uma teoria enunciativa, 
tal qual Cordero (1993, p. 61-62) nos explica na "Introdução". Segundo ele, a teoria platônica da enunciação é uma aplicação, ao domínio da linguagem, de sua nova concepção do ser como potência de comunicação, da relação entre as categorias da realidade e o não-ser como alteridade.

Para Paviani (1993), encontramos no Sofista, o discurso determinado pela relação entre o nome e o verbo. O significado da proposição provém dessa ligação. 0 que torna um discurso verdadeiro ou falso é o fato dele se referir a alguma coisa. Uma sequência de nomes ou de verbos, sem associação entre eles, não forma um discurso. É preciso, portanto, reunir o nome e o verbo. "O discurso não enuncia simplesmente uma coisa, mas enuncia, de uma coisa, algo existente em relação a ela. Unindo um nome e um verbo, o falante liga um agente a uma ação, registrando nos sinais (o discurso) a comunhão existente nas coisas representadas por esses sinais (262e)" (NEVES, 1987, p. 56). Sendo assim, todo discurso pode ser verdadeiro ou falso, o discurso verdadeiro é aquele que diz de alguém o que é tal como é, e falso o que enuncia "o Outro como sendo o Mesmo, e o que não é como sendo" (PAVIANI, 1993, p. 49).

O diálogo Sofista nos apresenta, portanto, uma teoria da alteridade, como Ducrot ressaltou, que também se encontra no discurso. "Pensar que sou este ou aquele é sempre imaginar alguém que me vê como este ou como aquele, e cujo olhar me constitui, (...) e se a língua é, antes de mais nada, o terreno onde afronto outrem, não nos surpreenderemos com o fato de a realidade linguística ser, como viu Saussure, fundamentalmente opositiva" (DUCROT, 2009, p. 11).

\section{Ser o que os outros não são: a alteridade em Saussure}

Colocar Saussure e Platão em relação não é muito usual nos estudos sobre a história da linguística. Alguns autores associam a obra de Saussure ao modelo teórico de pensadores como Aristóteles, Galileu e Condillac ${ }^{8}$, enquanto outros mencionam uma provável influência da sociologia de Emile Durkheim e da filosofia positivista 9 . A contribuição de comparatistas e neogramáticos é indubitável e, segundo Faraco (2011), os trabalhos do estudioso alemão Humboldt e do linguista americano Whitney foram fundamentais para a construção da ideia da língua como um sistema de signos independente (imanência).

Porém, antes de pensarmos em possíveis influências, é preciso reconhecer que o pensamento de Saussure representa uma grande mudança no campo dos estudos linguísticos. Suas concepções abriram espaço para a construção de uma verdadeira ciência da linguagem, cujo verdadeiro e único objeto de estudo, a língua, passou a ser considerado em si mesmo e por si mesmo. Além de demonstrar que a "língua poderia (e deveria) ser tratada exclusivamente como uma forma (livre das suas substâncias)" (FARACO, 2011, p. 28), Saussure nos mostra que a língua se constitui a partir de um "jogo sistêmico de relações de oposição - funcionando este jogo de tal modo que nada é num sistema linguístico senão por uma teia de relações de oposição" (idem, p. 28).

Embora reconhecendo o caráter fundador do "gesto epistemológico saussuriano", Faraco (2011) afirma que essa formulação é resultado do trabalho de linguistas precedentes, que já desenvolviam uma concepção de língua como um todo organizado. Isto é, segundo o autor, um "senso de sistema autônomo" já permeava o trabalho de alguns linguistas ao longo do século XIX. O próprio Whitney, por exemplo, ao considerar a língua como uma instituição social, insistindo no caráter arbitrário dos signos e, com isso,

8 Ver MOUNIN, George. Saussure: presentación y textos. Barcelona: Editorial Anagrama, 1969 e BOUQUET Simon. Introdução à leitura de Saussure. São Paulo: Cultrix, 2000

9 Ver CULLER, Jonathan. As ideias de Saussure. São Paulo: Cultrix, 1979 e LODER, Letícia L. \& FLORES, Valdir do Nascimento. Ferdinand de Saussure e a sociologia durkheimiana. Organon, Porto Alegre, $\mathrm{n}^{\mathrm{O}}$ 40/41, jan-dez, 2006, p. 273-294. 
colocando “a Linguística em seu verdadeiro eixo” (SAUSSURE, 2012, p. 116), conquistou o reconhecimento de Saussure.

Por outro lado, sem desmerecer a visível influência de estudiosos como Whitney (talvez o mais admirado por Saussure), nós acreditamos que o princípio que norteou as formulações do linguista genebrino (o princípio que faz da língua "um sistema do qual todas as partes podem e devem ser consideradas em sua solidariedade sincrônica" (SAUSSURE, 2012, p. 128)), está apoiado em reflexões filosóficas anteriores. Na verdade, muito anteriores, mas que deixaram marcas em toda a cultura ocidental e levantam temas até hoje debatidos. Referimo-nos à teoria platônica da alteridade, apresentada no diálogo Sofista.

Na primeira parte deste artigo, procuramos mostrar como Platão desenvolveu uma teoria da alteridade que, nas palavras de Ducrot, "ainda não deixa de causar espanto aos que querem lê-la bem e cuja necessidade a Linguística moderna vem redescobrindo desde Saussure" (2009, p. 10). Agora, nossa intenção é explicitar que a afirmação encontrada no $C L G$, de que "na língua só existem diferenças" (SAUSSURE, 2012, p. 167), fundamenta-se na ideia segundo a qual a essência do diferente (do Outro) permeia a todos os signos, "uma vez que cada um deles é diferente dos demais, não por razão de sua própria natureza, mas porque partilha da forma ou ideia do diferente" (Sofista, 255e).

À primeira vista, pensar que a construção de um conceito tão significativo na reflexão saussuriana, como é o caso do valor linguístico, possa ter uma fundamentação filosófica, notadamente metafísica, pode parecer paradoxal. A preocupação em garantir um estatuto científico ao estudo da língua poderia ter afastado Saussure de uma abordagem baseada em pressupostos filosóficos. Segundo Normand, "a ideologia científica da época, que limitava ao dado diretamente observável o domínio do pesquisador e não via na abstração senão a especulação filosófica, opunha-se às formulações explicitamente abstratas" (2009, p. 59-60). Isso explicaria a presença de expressões como "entidades concretas", "objeto de natureza concreta", etc., que não correspondem à ideia, claramente exposta nos Escritos de linguística geral (doravante $E L G$ ), de que a língua não é matéria, não tem substrato ${ }^{10}$.

No entanto, conforme os editores Bouquet e Engler (2004) afirmam, no prefácio aos $E L G$, o conjunto das reflexões saussurianas, comumente chamado de linguística geral, estende-se a três campos do saber ${ }^{11}$, entre os quais se vislumbra uma "especulação analítica sobre a linguagem", (2004, p. 12), qualificada, diversas vezes, pelo próprio Saussure como filosófica.

Essa fundamentação filosófica da reflexão saussuriana, aparentemente fragmentada no $C L G$, aparece com bastante vigor nos $E L G$, sobretudo nos manuscritos que compõem a primeira parte intitulada "Sobre a essência dupla da linguagem". Nesse conjunto de documentos encontramos uma ideia que Saussure ressalta insistentemente, resumindo-a ao que chama de "princípio das OPOSIÇÕES, ou dos VALORES RECÍPROCOS, ou das QUANTIDADES NEGATIVAS e RELATIVAS que criam um estado de língua" (SAUSSURE, 2004, p. 27).

Contudo, no presente trabalho, não adentraremos no que se poderia chamar de "pensamento puro" do mestre genebrino, proveniente do seu próprio "punho". Os manuscritos de Saussure, apresentados nos ELG, ainda não eram conhecidos quando Ducrot tomou contato com a obra saussuriana, nos anos de 1960. Por isso, vamos explorar a teoria do valor linguístico, encontrada sobretudo nos capítulos III, IV e $\mathrm{V}$ da segunda parte do $C L G$. Para compreendê-la é preciso situá-la no complexo aparato conceitual saussuriano. Só então poderemos associá-la à teoria da alteridade de Platão.

${ }^{10}$ Ver DEPECKER, Loïc. Compreender Saussure a partir dos manuscritos. Petrópolis, RJ: Vozes, 2012

${ }^{11}$ Os três campos do saber mencionados pelos editores são: 1 o epistemologia; 2o especulação analítica; $3^{\circ}$ reflexão prospectiva sobre uma disciplina. Para saber mais sobre os três campos do saber da linguística reflexão prospectiva sobref́l Saussuriana, além do Prefácio aos ELG, ver BOUQUET, Simon. Introdução à leitura de Saussure. São
Paulo: Cultrix, 2000. 
Como sabemos, Saussure estava "muito insatisfeito" e "preocupado" com os rumos que a Linguística parecia tomar, entre a Gramática Comparativa e o movimento dos neogramáticos. O método comparativo, segundo o linguista genebrino, "acarreta todo um conjunto de conceitos errôneos, que não correspondem a nada na realidade e que são estranhos às verdadeiras condições de toda linguagem" (SAUSSURE, 2012, p. 34). Quanto aos neogramáticos, embora tenham o mérito de "colocar em perspectiva histórica todos os resultados da comparação, e por ela encadear os fatos em sua ordem natural" (ibidem, p. 35-36), não conseguiram esclarecer problemas fundamentais em torno dos fatos da língua.

Assim, entre as tarefas da Linguística elencadas por Saussure, estão a de delimitar-se e definir-se a si própria. Para atingir esse objetivo, tornavase imprescindível estabelecer um aparato metodológico que fosse capaz de dar conta do fenômeno linguístico em toda a sua complexidade. De modo que, seja qual for o ponto de vista que se adote para estudar o fenômeno linguístico, ele "apresenta perpetuamente duas faces que se correspondem e das quais uma não vale senão pela outra” (SAUSSURE, 2012, p. 39). Eis aí um princípio que permeia todo o conjunto de ideias e definições que marcam a teoria saussuriana: o princípio da essência dupla da linguagem ${ }^{12}$. Segundo Benveniste, esse princípio determina que:

Tudo na linguagem tem de ser definido em termos duplos; tudo traz a marca e o selo da dualidade opositiva: dualidade articulatória/acústica; dualidade do som e do sentido; dualidade do indivíduo e da sociedade; dualidade da língua e da fala; dualidade do material e do não-substancial; dualidade do "memorial" (paradigmático) e do sintagmático; dualidade da identidade e da oposição; dualidade do sincrônico e do diacrônico, etc. (BENVENISTE, 2005, p. 43).

\footnotetext{
${ }^{12}$ Princípio que muitas vezes foi interpretado de maneira equivocada, na perspectiva das "dicotomias" saussurianas, que põe em pura oposição dualidades que estão estreitamente ligadas e que se implicam mutuamente.
}

Diante de tantas dualidades ${ }^{13}$, o objeto de estudo da Linguística se apresenta como um "aglomerado confuso de coisas heteróclitas" (SAUSSURE, 2012, p. 40), de modo que "é necessário colocar-se primeiramente no terreno da língua e tomá-la como norma de todas as outras manifestações da linguagem" (ibidem, p. 41). A delimitação do objeto de estudo se dá simultaneamente ao estabelecimento de uma metodologia, que permita analisá-lo em si e por si mesmo, visto que a língua é "um todo por si e um princípio de classificação" (SAUSSURE, 2012, p. 41) ou seja, "um sistema que conhece somente sua ordem própria" (ibid., p. 55).

Nessa definição de língua evidencia-se a posição epistemológica que apregoa a anterioridade do ponto de vista em relação ao objeto de estudo: "é o ponto de vista que cria o objeto" (SAUSSURE, 2012, p. 39). Afinal, dada a peculiaridade da língua, a Linguística, diferentemente de outras ciências, como a Física ou a Biologia, não lida com um objeto dado, um conjunto de coisas evidentes, pelo contrário, "não há nenhuma entidade linguística que possa ser dada, que seja dada imediatamente pelo sentido; nenhuma que exista fora da ideia que lhe pode ser vinculada" (SAUSSURE, 2004, p. 23).

Dito de outro modo, a língua não é um objeto material, não é substância, "a língua não comporta ideias nem sons preexistentes ao sistema linguístico, mas somente diferenças conceituais e diferenças fônicas resultantes desse sistema" (SAUSSURE, 2012, p. 167). Considerando que as entidades linguísticas não se apresentam por si mesmas ao linguista, "é necessário colocarmo-nos diante do ato individual que permite reconstituir o circuito da fala" (ibid., p. 43), ato que pressupõe pelo menos

${ }^{13}$ Esse conjunto de dualidades presente na teoria saussuriana levaram Bagno (2011) a desenvolver uma crítica ao que chama de "platonismolingú́stico". Segundo ele, a filosofia dualista de inspiraça pl exercu (ex" exc) uma "pesada" influencia sobr "dicotomias" saussurianas. 
dois indivíduos para que se realize. Esse sistema de "diferenças" está, portanto, indissociavelmente ligado à fala (ou discurso), que o precede historicamente e sem a qual não poderia ser apreendido pelo linguista.

Por outro lado, é a língua que permite que "a fala seja inteligível e produza todos os seus efeitos" (SAUSSURE, 2012, p. 51), pois se configura como "um conjunto de convenções necessárias, adotadas pelo corpo social para permitir o exercício dessa faculdade nos indivíduos" (ibid., p. 41). Nesse sentido, é a coletividade que cria o sistema linguístico e estabelece os valores que possibilitarão a comunicação. Esses valores, que determinam o funcionamento da língua, são acionados, ativa ou passivamente, em nossa mente através de uma "faculdade de associação e de coordenação" (SAUSSURE, 2012, p. 44) que "desempenha o principal papel na organização da língua enquanto sistema" (idem, p. 44).

A ideia de sistema remete, invariavelmente, à ideia de um grupo ou conjunto de elementos, materiais ou ideais, que coordenados entre si funcionam como uma estrutura organizada. Segundo Normand, Saussure adota o termo sistema, que, como vimos, já era utilizado pelos linguistas, em um sentido muito preciso, "explicitado como funcionamento ou mecanismo" (2009, p. 50) e que remete a uma característica fundamental das entidades linguísticas: "a de que é impossível apreendê-las fora do sistema específico em que elas são tomadas, pois é nele que está seu modo de realidade" (idem, p. 50). A língua "é um sistema do qual todas as partes podem e devem ser consideradas em sua solidariedade sincrônica” (SAUSSURE, 2012 p. 128).

Nesse sentido, as entidades linguísticas só possuem existência para um indivíduo, para um sujeito falante, "nas relações recíprocas que mantêm e que lhes dão sentido" (NORMAND, 2009, p. 50) em um determinado estado de língua. É somente na sincronia ${ }^{14}$ que se pode apreender o funcionamento do sistema. Logo, partir do sistema implica adotar uma diretiva metodológica que exclua, no estudo da língua, a consideração de elementos externos: sejam eles históricos ou sociais. Assim, poderíamos comparar o sistema linguístico saussuriano a uma máquina, sendo que o valor constitui e se constitui no funcionamento das engrenagens que compõem a máquina. Abordadas fora das relações próprias ao sistema, as entidades linguísticas "não passam de elementos materiais desprovidos de significação" (idem, p. 50).

Para Saussure, a língua é um sistema de signos. O signo, por sua vez, também tem uma natureza dupla, pois é constituído de duas faces relacionadas entre si, e inseparáveis, o significante e o significado. Trata-se de uma ligação arbitrária e, mais uma vez, nos valemos da leitura de Normand, que afirma:

aplicar [...] o princípio do arbitrário é afastar, na descrição, qualquer ponto de vista diretor, e, em primeiro lugar, o do signo como representante de uma ideia. [...] Partir do arbitrário é também afastar o sujeito falante em suas particularidades e em sua vontade de significar, pois o signo só é arbitrário porque é social, imposto por regras que ninguém pensa discutir (NORMAND, 2009, p. 69-70)

Ocorre que o signo só tem sentido se for determinado por sua relação com outros signos. As relações entre os signos, com as quais se constitui um enunciado, também são arbitrárias. "São regras próprias a cada língua, restrições contingentes" (NORMAND, 2009, p. 65) que provêm "do fato de se tratar de um jogo, ou seja, de um funcionamento formal” (ibidem, p. 66),

${ }^{14}$ Para Saussure, a Linguística sincrônica é aquela que se ocupa "das relações lógicas e psicológicas que unem os termos coexistentes e que for aquela que se octais como são percebidos pela que una", em oposiç̃̃o à Linguística diacrônica que estuda "as relaç̃̃es que unem termos succiencia cõo percebidos por a a Linguistica dicichos sistema entre si" (2012 p. 142). 
"de uma ordem interna" (ibid., p. 71), "uma ordem de puros valores" (ibid., p. 72). O valor linguístico resulta, portanto, da presença de outros signos, tanto no eixo associativo (paradigmático) quanto no eixo sintagmático. Por isso, a noção de sistema implica a de relação e da noção de relação decorre a noção de valor.

A noção de valor é extremamente complexa na obra saussuriana (de fato, trata-se de uma teoria do valor) na medida em que coordena dois fatos, eles mesmos complexos. Segundo Bouquet (2000), o primeiro fato (o do valor in absentia) faz corresponder termo a termo a relação que apontamos anteriormente, ou seja, a teoria do valor e a teoria do arbitrário. Resumidamente, o autor afirma que a noção de valor recobre cinco fatos, pertencentes a duas categorias.

A primeira categoria abrange o valor interno do signo que, por sua vez, compreende três aspectos: 1 o - o significante responde pelo seu significado (o significado é o valor desse significante); $2^{\circ}$ - o significado responde pelo seu significante (o significante é o valor desse significado); $3^{\circ}$ - significante e significado respondem simultaneamente um pelo outro (o significante e o significado são simultaneamente o valor um do outro (BOUQUET, 2000, p. 258).

A segunda categoria do valor in absentia corresponde ao valor sistêmico do signo. $\mathrm{O}$ valor sistêmico abarca o valor sistêmico fonológico e o valor sistêmico semântico. Nesse caso, não estamos diante do vínculo arbitrário entre dois objetos dessemelhantes unidos por um vínculo de necessidade como vimos acima, mas "do arbitrário do vínculo multidimensional entre um objeto e todos os outros objetos da mesma natureza, ou seja, todas as unidades significantes e todas as unidades significadas que constituem a classe à qual pertence esse objeto" (BOUQUET, 2000, p. 236). 0 valor interno e o valor sistêmico que conjugam-se para formar o valor in absentia formam apenas uma parte do valor semântico de um signo.
O segundo fato, relativo à complexidade da noção valor, corresponde ao chamado valor in praesentia e associa ao valor interno (in absentia), proveniente do arbitrário da língua, um valor proveniente do fato sintagmático (BOUQUET, 2000, p. 268). É na combinação desses dois fatos que Saussure vê a essência do fato semântico.

Com efeito, Saussure reconhece a complexidade da proposta e vê nela um verdadeiro paradoxo: "de um lado, o conceito nos aparece como a contraparte da imagem auditiva no interior do signo, e, de outro, esse mesmo signo, isto é, a relação que une seus dois elementos, é também, e de igual modo, a contraparte dos outros signos da língua" (SAUSSURE, 2012, p. 161).

Substituindo os termos conceito e imagem auditiva por significado e significante, respectivamente, Ducrot (2006) resume o paradoxo da seguinte maneira: de um lado, o significado e o significante são constituintes internos do signo, inseparáveis um do outro, e um só existe por causa do outro. De outro lado, o signo, a saber, a relação que os constitui um e outro, só é o conjunto de relações que os unem com os outros signos da língua, isto é, com outras relações significado-significante.

Os signos são, assim, as engrenagens da complexa máquina que é a língua. Ou, em vez de engrenagens, poderíamos pensar nos signos como peças de um jogo, exatamente como Saussure faz ao comparar o jogo da língua a uma partida de xadrez: "uma posição de jogo corresponde de perto a um estado de língua. $\mathrm{O}$ valor respectivo das peças depende da sua posição no tabuleiro, do mesmo modo que na língua cada termo tem seu valor pela oposição aos outros termos" (SAUSSURE, 2012, p. 130).

Como podemos observar, "a oposição, para Saussure, é constitutiva do signo da mesma forma que a alteridade é, para Platão, constitutiva das ideias" (DUCROT, 2009, p. 10-11). Há inúmeras passagens no CLG em que se afirma, recorrentemente, a importância do "princípio de diferenciação", que na língua "tudo é oposição", que seu funcionamento não passa de um "jogo 
das oposições linguísticas" (SAUSSURE, 2012, p. 169), enfim, que na língua "tudo se reduz a diferenças" (ibid., p. 177).

Mais do que isso, Saussure concebe a essência do signo como potencialmente relativa. $\mathrm{O}$ signo é essencialmente em virtude de seu caráter associativo com outro(s) signo(s): "o que haja de ideia ou de matéria fônica num signo importa menos do que existe ao redor dele nos outros signos" (SAUSSURE, 2012, p. 167-8). É por isso que os signos são valores, pois a noção de valor supõe a existência de uma relação: tanto aquela que reune, no signo, um significado e um significante, quanto aquela que faz dele (o signo) parte do sistema, cujo valor surge, justamente, da oposição com outros signos.

Para Platão, vale lembrar, é a possibilidade de comunicação com outros seres, com outras formas, que permite que alguma coisa seja, que constitua sua essência. De fato, a palavra essência deriva do verbo latino esse, 'ser'. Reconstituindo a argumentação desenvolvida na segunda parte do CLG, dedicada à Linguística sincrônica, podemos verificar em que medida a teoria do valor se fundamenta no princípio que Platão descobre em sua investigação sobre o ser: a alteridade.

Inicialmente, Saussure afirma que o objeto da Linguística sincrônica geral é "estabelecer os princípios fundamentais de todo sistema idiossincrônico" (SAUSSURE, 2012, p. 145). Mas, quais são esses "princípios essenciais" sem os quais "não se poderiam abordar os problemas mais especiais da estática, nem explicar os pormenores de um estado de língua” (idem, p. 145)? A resposta vai surgindo ao mesmo tempo em que se constata que fazer a Linguística de um estado de língua "apresenta dificuldades bem maiores" das que a linguística histórica enfrenta, pois a Linguística15 "se ocupa de valores e relações coexistentes" (idem, p. 145).

${ }^{15}$ Aqui o termo Linguística deve ser compreendido como sinônimo de linguística sincrônica (estática
ou de um estado de língua). Vale lembrar que, para Saussure, é somente na sincronia que se pode apreender o funcionamento do sistema.
É preciso, portanto, determinar que princípios fundamentam os signos e suas relações. Ou seja, impõe-se a necessidade de delimitar a natureza das entidades linguísticas (os signos) e de compreender o mecanismo de suas relações. Segundo Saussure, dois princípios dominam toda a questão: "1o - A entidade linguística só existe pela associação do significante e do significado; se se retiver apenas um desses elementos, ela se desvanece" (SAUSSURE, 2012, p. 147); “2o - A entidade linguística não está completamente determinada enquanto não esteja delimitada, separada de tudo o que a rodeia na cadeia fônica. São essas entidades delimitadas ou unidades que se opõem no mecanismo da língua" (ibid., p. 148).

Devemos observar que a ideia de alteridade subjaz aos dois princípios. Na realidade, esses princípios estão estreitamente relacionados, ambos se implicam mutuamente. No entanto, para facilitar nossa leitura, vamos analisálos separadamente. $\mathrm{O}$ primeiro remete à natureza do signo linguístico: o arbitrário "laço que une o significante ao significado" (SAUSSURE, 2012, p. 108) que nos permite "compreender por que a língua não pode ser senão um sistema de valores puros" (ibid, p. 158). É a relação entre dois elementos distintos que constitui sua essência. Um significado sem significante ou um significante sem significado não valem nada, não são uma entidade linguística. "Na língua, como em todo sistema semiológico, o que distingue um signo é tudo o que o constitui. A diferença é que faz a característica, como faz o valor e a unidade" (ibid., p. 169).

O segundo princípio, por sua vez, nos faz pensar na ideia do signo em sua totalidade, inserido no sistema e, portanto, apto a ser delimitado em razão do que o rodeia e a ele se opõe. Num primeiro momento, Saussure sugere uma aproximação dessa entidade linguística à noção de "palavra", mas acaba por renunciar à ideia, sobretudo pelas dificuldades de definição do que seja exatamente uma palavra e pela incompatibilidade da mesma com o que se busca distinguir. Assim, quando "uma ciência não apresenta unidades 
concretas imediatamente reconhecíveis, é porque elas não são essenciais" (SAUSSURE, 2012, p. 151). Por isso, é necessário "escapar às ilusões" (ibid., p. 156) e, a despeito da "importância capital das unidades", é "preferível abordar o problema pelo aspecto do valor, que é, a nosso ver, seu aspecto primordial" (ibid., p. 157).

É a noção de valor que permite, finalmente, interligar os dois princípios elencados acima. A teoria do valor, que, segundo Normand, "ocupa o lugar mais importante no Curso" (2009, p. 64), é apresentada no capítulo IV da segunda parte, intitulado $O$ valor linguístico. 0 valor intervém em todas as dimensões do signo: cada uma das faces do signo, significado e significante; e o signo em sua totalidade.

Abstraindo a indissolúvel união entre significado e significante, a análise do valor em seu "aspecto conceitual" apresenta-se sempre condicionada à ideia constitutiva da diferença, da alteridade: "Quando se diz que os valores correspondem a conceitos, subentende-se que são puramente diferenciais, definidos não positivamente por seu conteúdo, mas negativamente por suas relações com os outros termos do sistema. Sua característica mais exata é ser o que os outros não são" (SAUSSURE, 2012, p. 164, grifo nosso). O mesmo acontece quando se analisa a "parte material" do valor: "é evidente, mesmo a priori, que jamais um fragmento de língua poderá basear-se, em última análise, em outra coisa que não seja sua não coincidência com o resto" (ibid., p. 165, grifo nosso).

Porém, acreditamos que a separação entre o valor conceitual e o valor material surge apenas pela necessidade de descrição. A oposição que nos parece fundamental surge na consideração do signo em sua totalidade. É aqui que a teoria do valor parece tomar a dimensão que Saussure realmente queria ressaltar: "o que haja de ideia ou de matéria fônica num signo importa menos do que existe ao redor dele nos outros signos" (SAUSSURE, 2012, p. 167-8, grifo nosso). A verdadeira natureza das unidades linguísticas ultrapassa sua identidade conceitual ou material. O que se revela, não ao olhar despretensioso do usuário da língua, afinal as entidades da língua "não se apresentam por si mesmas à nossa observação", mas, ao olhar do linguista, é que, na língua, "todos os termos são solidários e o valor de um resulta somente da presença simultânea de outros" (SAUSSURE, 2012, p. 161). Assim como para Platão, "cada coisa é idêntica a ela mesma, mas ela também é diferente (ou "outra") das outras" (CORDERO, 1993, p. 60), para Saussure "o mecanismo linguístico gira todo ele sobre identidades e diferenças, não sendo estas mais que a contraparte daquelas" (SAUSSURE, 2012, p. 154).

Ora, trata-se mais uma vez de reconhecer que "a língua [...] não pede mais que a diferença” (SAUSSURE, 2012, p. 166). Ou melhor, "que na língua só existem diferenças" (ibid., p. 167). O que Saussure ressalta com essas afirmações é que o mais importante no estudo da língua são as relações, as combinações entre os elementos que a compõem e o valor decorrente dessas relações, pois, "assim como o jogo de xadrez está todo inteiro na combinação das diferentes peças, também a língua tem o caráter de um sistema baseado completamente na oposição de suas unidades concretas" (SAUSSURE, 2012, p. 152).

Cabe, por fim, determinar como funcionam as relações que fundamentam o mecanismo da língua. Segundo Saussure, "as relações e as diferenças entre termos linguísticos se desenvolvem em duas esferas distintas" (2012, p. 171): estamos adentrando na especificidade das relações sintagmáticas e associativas.

As relações sintagmáticas se estabelecem a partir do encadeamento dos termos no discurso. Em razão do caráter linear da língua, os termos se combinam e "se alinham um após o outro", recebendo o nome de sintagmas:

O sintagma se compõe sempre de duas ou mais unidades consecutivas (por exemplo: re-ler, contra todos; a vida humana; Deus é bom; se fizer bom tempo, sairemos etc.). Colocado num sintagma, um termo só adquire seu valor porque se opõe ao que o precede ou ao que o segue, ou a ambos (SAUSSURE, 2012, p. 171-2) 
A noção de sintagma, tal como colocada no $C L G$, suscita uma certa dúvida quanto à sua inserção no domínio da língua, uma vez que a frase, "tipo por excelência de sintagma” pertence à fala. É uma questão que permanece em aberto. No entanto, uma resposta parece aflorar na continuidade da argumentação. A sintagmatização ocorre na linearidade da fala, pela escolha do sujeito falante, mas sujeita às regras impostas pela língua: "cumpre atribuir à língua, e não à fala, todos os tipos de sintagmas construídos sobre formas regulares" (SAUSSURE, 2012, p. 173). Sem dúvida, uma referência à analogia. De qualquer maneira, essa questão foge por demais ao nosso tema.

A questão que se impõe aqui é que, nas relações sintagmáticas "o todo vale pelas suas partes, as partes valem também em virtude de seu lugar no todo" (SAUSSURE, 2012, p. 177), de modo que os agrupamentos sintáticos se constituem com base em "um vínculo de interdependência; eles se condicionam reciprocamente" (idem, p. 177). É o princípio da alteridade platônica que, mais uma vez, se sobressai. Princípio que também se destaca nas relações associativas.

As relações associativas evocam elementos ausentes do discurso, se estabelecem na memória e "fazem parte desse tesouro interior que constitui a língua de cada indivíduo" (SAUSSURE, 2012, p. 172). “Uma palavra qualquer pode sempre evocar tudo quanto seja suscetível de ser-lhe associado de uma maneira ou de outra" (ibidem, p. 175), ou seja, diferentes aspectos do signo podem produzir uma série de relações entre significados ou entre significantes. É o que sugere a figura da página 175 (SAUSSURE, 2012): a palavra ensinamento surge "como o centro de uma constelação", da qual convergem termos, de "número indefinido" e de "ordem indeterminada", que se associam em razão de identidade lexical (ensinar, ensinemos) ou conceitual (aprendizagem, educação), como também, termos que se associam à identidade do significante (elemento, desfiguramento, lento, armamento).
Finalmente, é o conjunto das relações sintagmáticas e associativas que constitui e determina o mecanismo da língua. São essas relações de "solidariedade recíproca" (SAUSSURE, 2012, p. 177) que conferem sentido à língua. $\mathrm{O}$ valor de um signo é determinado a partir do funcionamento simultâneo dessas duas formas de relação. É o laço que une um signo a outro que constitui seu valor e que faz dele um signo. É na interseção do eixo associativo com o eixo sintagmático que invocamos "todo um sistema latente, graças ao qual se obtêm as oposições necessárias à constituição do signo" (ibid., p. 179). Segundo Ducrot, trata-se, afinal, da "ideia, evidente desde que nos disponhamos a considerá-la, de que um objeto só pode ser descrito em relação a outros objetos, e que não há, se tomarmos as palavras ao pé da letra, nenhum sentido em visualizá-lo 'em si mesmo'” (1987, p. 67).

E, assim, fechamos nossa reconstituição sobre a argumentação desenvolvida por Saussure, ao longo da segunda parte do $C L G$, tendo como foco a teoria do valor. Nessa perspectiva, "o valor de uma palavra - ou seja, sua realidade linguística - é o que a opõe às outras palavras. Indo mais longe, é a de se opor às outras. Seu ser é ser outro" (DUCROT, 2009, p. 11). Conhecendo profundamente a filosofia de Platão, Ducrot percebeu, na teoria do valor linguístico, o papel constitutivo da alteridade, tal como foi apresentada no diálogo Sofista:

Se o Movimento é diferente do Repouso, não é porque o Movimento possui em si mesmo tal ou qual característica positiva que podemos perceber quando o consideramos isoladamente, característica que se revelaria diferente daquelas, igualmente positivas, que possui o Repouso. Ao contrário, a diferença entre o Movimento e o Repouso é constitutiva dessas mesmas noções. 0 Movimento aquilo que ele é, pelo fato de que ele é outro, diferente do Repouso, do Mesmo.. etc. (DUCROT, 2009, p. 10).

Essa percepção, de certo modo, foi o que permitiu a Ducrot desenvolver uma teoria linguística que hoje conhecemos como Semântica 
Argumentativa. Foi a noção de valor, fundamentada na alteridade, que o lançou na pesquisa linguística e, desde então, vem norteando todo o seu trabalho em semântica ${ }^{16}$. A ideia de dar à alteridade um valor constitutivo direcionou o olhar de Ducrot, permitindo-lhe levar a noção de valor linguístico para o uso efetivo da língua, demonstrando que o valor argumentativo de uma palavra é, por definição, a orientação que essa palavra dá ao discurso. Assim, a ideia central da semântica linguística, desenvolvida por Ducrot e colaboradores, é a de que o emprego de uma palavra faz possível ou impossível uma certa continuação do discurso e o valor argumentativo dessa palavra é, justamente, o conjunto dessas possibilidades ou impossibilidades de continuação discursiva que seu emprego determina.

A teoria da polifonia de Ducrot também funda o sentido sobre a alteridade, na medida em que "o sentido de um enunciado descreve a enunciação como uma espécie de diálogo cristalizado, em que várias vozes se entrechocam" (DUCROT, 1987, p. 9). Dessa forma, acreditamos que a Semântica Argumentativa se constitui a partir de um diálogo interdisciplinar, entrelaçando a alteridade platônica ao estruturalismo de Saussure e desenvolvendo o que Ducrot chama de "platonismo saussuriano" (2009, p. 11). Mas isso é assunto para um outro trabalho.

\section{Agradecimentos}

À Coordenação de Aperfeiçoamento de Pessoal de Nível Superior CAPES, pela bolsa de estudos.

\footnotetext{
${ }^{16}$ Ver DUCROT Oswald. La Sémantique Argumentative peut-elle se réclamer de Saussure? In SAUSSURE Louis de (org.). Nouveaux regards sur Saussure. Genebra: Librairie Droz S. A., 2006.
}

\section{Referências}

ARRIVÉ, Michel. Linguagem e psicanálise, linguística e inconsciente: Freud, Saussure, Pichon, Lacan. Trad. Lucy Magalhães. Rio de Janeiro: Jorge Zahar Ed., 1999.

BAGNO, Marcos. Gramática pedagógica do português brasileiro. São Paulo: Parábola Editorial, 2011.

BENVENISTE, É. Problemas de linguística geral I. Trad. Maria da Glória Novak e Maria Luisa Neri. Revisão Isaac Nicolau Salum. 5. ed. Campinas: Pontes, 2005.

BOUQUET, Simon. Introdução à leitura de Saussure. Trad. Carlos Augusto Leuba Salum e Ana Lúcia Franco. São Paulo: Cultrix, 2000.

BRISSON, Luc; PRADEAU, J-F. Vocabulário de Platão. Trad. Claudia Berliner. Revisão técnica Tessa Moura Lacerda. São Paulo: WMF Martins Fontes, 2010.

CAMARA JR., Joaquim Mattoso. História da Linguística. 7 ed. Petrópolis, RJ: Vozes, 2011. CORDERO, Nestor-Luis. Introduction. In: PLATON, Le Sophiste. Paris: GF-Flammarion, 1993.

CULLER, Jonathan. As ideias de Saussure. Trad. Carlos Alberto da Fonseca. São Paulo: Cultrix, 1979.

DEPECKER, Loïc. Compreender Saussure a partir dos manuscritos. Trad. Maria Ferreira. Petrópolis, RJ: Vozes, 2012.

DUCROT, Oswald. Estruturalismo e linguística. Trad. José Paulo Paes. São Paulo: Cultrix, 1970.

. O dizer e o dito. Trad. Revisão técnica da tradução Eduardo Guimarães. Campinas Pontes, 1987.

. La Sémantique Argumentative peut-elle se réclamer de Saussure? In: SAUSSURE, Louis de (org.). Nouveaux regards sur Saussure. Genebra: Librairie Droz, 2006.

. Prefácio. In: VOGT, Carlos. O intervalo semântico. Campinas: Unicamp, 2009.

SAUSSURE, Louis de; TODOROV, T. Dicionário enciclopédico das ciências da linguagem. São Paulo: Perspectiva, 2010.

FARACO, Carlos Alberto. Estudos pré-saussurianos. In: MUSSALIM, Fernanda; BENTES, Ana Christina (orgs.). Introdução à linguística: fundamentos epistemológicos. 5. ed. São Paulo: Cortez, 2011. Vol. 3. p. 27-51. 
LODER, Letícia L. \& FLORES, Valdir do Nascimento. Ferdinand de Saussure e a sociologia durkheimiana. Organon, Porto Alegre, n. 40/41, p. 273-294, jan.-dez. 2006.

MOUNIN, George. Saussure: presentación y textos. Barcelona: Editorial Anagrama, 1969.

NEVES, Maria Helena de Moura. A vertente grega da gramática tradicional. São Paulo: HUCITEC; Brasília: Editora Universidade de Brasília, 1987.

NORMAND, Claudine. Saussure. Trad. Ana de Alencar e Marcelo Diniz. São Paulo: Estação Liberdade, 2009.

PAVIANI, Jayme. Escrita e linguagem em Platão. Porto Alegre: EDIPUCRS, 1993.

. Tópicos para uma leitura de O Sofista. Revista Veritas, v. 42, n. 4. p. 937-943, dez. 1997.

PLATÃO. Diálogos I: Teeteto (ou Do conhecimento), Sofista (ou Do ser), Protágoras (ou Sofistas). Tradução, textos complementares e notas Edson Bini. Bauru, SP: Edipro, 2007. ROGUE, Christophe. Compreender Platão. Trad. Jaime A. Clasen. 6. ed. Petrópolis, RJ: Vozes, 2011.

SANTOS, José Gabriel Trindade. Platão: a construção do conhecimento. São Paulo: Paulus, 2012. (Coleção Cátedra).

SAUSSURE, Ferdinand de. Curso de linguística geral. BALLY, Charles; SECHEHAYE, Albert (orgs.); com a colaboração de RIEDLINGER, Albert. Prefácio à edição brasileira de Isaac Nicolau Salum. Trad. Antônio Chelini, José Paulo Paes, Izidoro Blikstein. 28. ed. São Paulo: Cultrix, 2012.

Escritos de linguística geral. BOUQUET, Simon; ENGLER, Rudolf (orgs.); com a colaboração de WEIL, Antoinette. Trad. Carlos Augusto Leuba Salum e Ana Lúcia Franco. São Paulo: Cultrix, 2004.

SOUZA, Eliane Christina de. Discurso e ontologia em Platão: um estudo sobre o sofista. Ijuí/RS: Ed. Unijuí, 2009. 208 p. (Coleção filosofia, 26).

Recebido em 20/10/2015.

Aceito em 28/01/2016 